\title{
Espaços livres para Brincar: Análise com foco na Proteção e Segurança ${ }^{1}$
}

\section{Open Play Spaces: Analysis focused on Protection and Security}

Sangali de Mello, Giullianna da Silva '; Andara Ramos, Larissa Leticia 2;

\author{
Jesus, Luciana Aparecida Netto 3 ; Conde, Karla Moreira ${ }^{4}$ \\ I Universidade Vila Velha (UVV), gsangali99@gmail.com \\ 2 Universidade Vila Velha (UVV), larissa.ramos@uvv.br \\ 3 Universidade Federal do Espírito Santo (UFES), luciana.a.jesus@ufes.br \\ ${ }_{4}^{4}$ Universidade Federal do Espírito Santo (UFES), karla.conde@ufes.br
}

\begin{abstract}
RESUMO
Esta pesquisa tem como tema os espaços livres de uso público, com foco nos espaços para brincar e seu papel no desenvolvimento da infância, no enriquecimento sociocultural e na construção de cidades inclusivas, acolhedoras e que potencializem o ciclo completo da convivência urbana. Busca realizar uma análise crítica dos espaços livres para práticas sociais, com foco na proteção e segurança destes espaços, tendo como recorte a Regional Grande Ibes, município de Vila Velha-ES. O presente trabalho de iniciação científica foi desenvolvido em parceria com a Universidade Vila Velha- ES e a Universidade Federal do Espírito Santo e consta de cinco etapas metodológicas: Contextualização do tema; Estudo de projetos exemplares; Mapeamento dos espaços livres para brincar no software ArcGis; Desenvolvimento dos indicadores e Análises dos espaços. O Estudo, além de fornecer reflexões sobre a proteção e segurança dos espaços para brincar, indicam que as áreas infantis mapeadas necessitam de um novo olhar voltado para atender as reais necessidades deste público.
\end{abstract}

Palavras-chave: Espaço público, Infâncias contemporâneas, Cidade inclusiva.

\begin{abstract}
This research has as its theme the open spaces, with a focus on play spaces and their role in the development of childhood, socio-cultural enrichment and the construction of inclusive, became cities that enhance the complete cycle of urban coexistence. It seeks to carry out a critical analysis of the free spaces for social practices, focusing on the protection and security of these spaces, with a study case of Regional Grande Ibes, Vila Velha-ES. This study was developed by a collaborative research network between the Federal University of Espírito Santo and Vila Velha University, in five methodological stages: Contextualization of the theme; Study of project examples; Mapping of play spaces in the software AcGis; Developed the analyses parameters and analysis these spaces. The Study, in addition to providing reflections
\end{abstract}

\footnotetext{
${ }^{1}$ MELLO, Giullianna; RAMOS, Larissa; JESUS, Luciana; CONDE, Karla. Espaços livres para Brincar: Análise com foco na Proteção e Segurança. In: II SIMPÓSIO NACIONAL DE GESTÃO E ENGENHARIA URBANA: SINGEURB, 2019, São Paulo. Anais... Porto Alegre: ANTAC, 2019.
} 
on the protection and safety of play spaces, indicates that the identified children's areas need a new vision aimed at meeting the real need of this public.

Keywords: Public space, Contemporary childhood, Inclusive city.

\section{INTRODUÇÃO}

O brincar é uma prática social fundamental para o desenvolvimento da criança. Configura a fase de aprendizado que contribui com a criatividade, a racionalização, o domínio de linguagem e a consciência de cidadania. A brincadeira permite que a criança se integre socialmente e desenvolva sentimentos de apropriação e pertencimento dentro do espaço urbano (DIAS, 2018).

Em decorrência do crescimento exacerbado dos interesses do mercado capitalista e da expansão dos espaços privados, a "cultura do medo" vem fortalecendo e tornando os espaços urbanos menos frequentados. A infância livre está sendo cada vez mais sufocada pelas transformações da sociedade atual e sendo prejudicada pela ausência de oportunidades de se apropriar da cidade, esvaziando os espaços públicos e perdendo sua representatividade (BAUMAN, 2001).

Dias (2018) afirma que as cidades ainda possuem um longo caminho na promoção da atenção às crianças, apresenta que os planejadores devem considerar a requalificação desses espaços integrados ao tecido urbano gerando vitalidade a cidade para que possam ser vividos pelas infâncias contemporâneas. Sendo assim, o planejamento do espaço público infantil deve atender as condições de apropriação e as restrições dos usuários, ressaltando que espaços seguros, acessíveis, atrativos e diversificados influenciam no processo de apropriação e vivência urbana (COTRIM, BICHARA, 2013).

Os espaços livres para brincar devem ainda dispor de equipamentos seguros, os espaços devem oferecer proteção, além de garantir o desenvolvimento e a ludicidade das crianças e adolescentes para que, assim, o brincar nos espaços livres possa ser resgatado. Nesse contexto, a pesquisa busca refletir sobre a proteção e segurança dos espaços para o brincar na cidade, tendo como recorte a Regional Grande Ibes, município de Vila Velha - ES. A discussão baseia-se na apropriação do espaço público, aliado às demandas sustentáveis e é realizada conforme parâmetros estudados por um grupo de pesquisa " Paisagem urbana e Inclusão" em parceria entre duas universidades do Espírito Santo - Brasil e que busca, a partir da avaliação de praças, discutir as diferenças de tratamento do espaço em diferentes pontos da região metropolitana de Vitória - ES.

Considerada a cidade mais antiga do Estado do Espírito Santo, Vila Velha é também a segunda mais populosa do Estado. É dividida em cinco regiões administrativas e possui 414.586 habitantes em uma área de unidade territorial de $209,965 \mathrm{~km}^{2}$ (VILA VELHA, 2008; IBGE, 2010).

A Grande lbes é a segunda regional em densidade habitacional. Possui bairros resultantes de loteamentos regularmente aprovados, de ocupação antiga e com o maior número de espaços livres de uso público do município. Além disso, de acordo com a SEMPLA (2013), cerca de $20 \%$ da população da Regional são crianças de 0 a 14 anos; público que merece atenção e sugere estudos que analisem a qualidade destes espaços.

\section{MÉTODO}

Para o desenvolvimento deste trabalho foi necessário um aprofundamento sobre o brincar no espaço público, tendo como principais autores Sartori, Alvarez e Sommerhalder (2015); Dias (2018); Medeiros (2016); Cotrim e Bichara (2013). Paralelamente à revisão bibliográfica, foram pesquisados exemplos de espaços públicos destinados ao público infantil com padrões inclusivos e educativos. A contextualização propiciou o mapeamento dos espaços a serem analisados, utilizando uma base cartográfica digital, realizada com o auxílio de um Sistema de Informação Geográfica (SIG), no caso o software ArcGIS (versão 10.5) a partir de dados cedidos pela Prefeitura municipal de Vila Velha. 
Com base no Índice de Caminhabilidade - iCam (BRASIL, 2018), elaborado pelo Instituto de Políticas de Transporte e Desenvolvimento - ITDP Brasil, foram selecionados critérios de análises considerando as adaptações necessárias para a aplicação em praças e ainda acrescendo indicadores específicos para o tema de estudo - espaços para brincar - visando garantir o conforto, a ludicidade e a segurança das crianças.

Os indicadores selecionados foram organizados em 4 categorias: "Proteção e Segurança", "Conforto e Imagem", "Acessos e Conexões" e "Sociabilidade, Usos e Atividades", subdivididas em 11 atributos e 36 indicadores. Vale destacar que o método avaliativo é organizado em categorias, atributos e indicadores. Conforme define o iCam (BRASIL, 2018), as categorias apresentam os principais parâmetros de referência para a avaliação. Os atributos foram criados como "sub-categorias", responsáveis pela maior organização e especificidade do indicador, estes responsáveis pela qualificação unitária do desempenho apresentado pelo objeto de estudo.

Sendo assim, tendo em vista que este artigo apresenta os resultados da aplicação e análise da categoria "Proteção e Segurança" nas praças da Regional Grande Ibes, foram selecionados 9 indicadores, com atributos com foco na segurança viária, segurança pública e proteção física - considerando o sistema de pontuação do próprio iCam: ótimo (3), bom (2), suficiente (1) e insuficiente (0), de acordo com o Quadro 1, a seguir.

Quadro 1 - Atributos e indicadores da categoria Proteção e segurança utilizados nesta pesquisa

\begin{tabular}{|c|c|c|c|c|c|c|}
\hline \multirow[b]{2}{*}{ Cat. } & \multirow[b]{2}{*}{ Atributo } & \multirow[b]{2}{*}{ Indicador } & \multicolumn{4}{|c|}{ Parâmetros de Análise } \\
\hline & & & $\begin{array}{l}\text { Pontuação } 3 \\
\text { (ótimo) }\end{array}$ & $\begin{array}{l}\text { Pontuaçāo } 2 \\
\text { (bom) }\end{array}$ & $\begin{array}{c}\text { Pontuação } 1 \\
\text { (suficiente) }\end{array}$ & $\begin{array}{l}\text { Pontuaçāo } 0 \\
\text { (insuficiente) }\end{array}$ \\
\hline \multirow{10}{*}{ 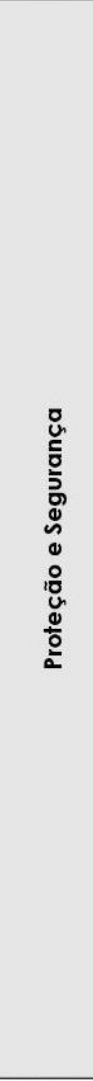 } & \multirow{3}{*}{$\begin{array}{l}\text { Segurança } \\
\text { Viária }\end{array}$} & Travessias & $\begin{array}{l}100 \% \text { das } \\
\text { travessias } \\
\text { cumprem os } \\
\text { requisitos }\end{array}$ & $\begin{array}{l}\geq 75 \% \text { das } \\
\text { travessias } \\
\text { cumprem os } \\
\text { requisitos }\end{array}$ & $\begin{array}{l}\geq 50 \% \text { das travessias } \\
\text { cumprem os requisitos }\end{array}$ & $\begin{array}{c}<50 \% \text { das travessias } \\
\text { cumprem os } \\
\text { requisitos }\end{array}$ \\
\hline & & \multirow[b]{2}{*}{$\begin{array}{l}\text { Tipologia da } \\
\text { rua }\end{array}$} & \multirow{2}{*}{$\begin{array}{l}\text { vias exclusivas } \\
\text { para pedestres }\end{array}$} & $\begin{array}{c}\text { vias } \\
\text { compartilhadas } \\
\text { velocidade } \leq 20 \\
\mathrm{~km} / \mathrm{h}\end{array}$ & $\begin{array}{c}\text { vias compartilhadas } \\
\text { velocidade } \leq 30 \\
\mathrm{~km} / \mathrm{h}\end{array}$ & $\begin{array}{c}\text { vias } \\
\text { compartilhadas } \\
\text { velocidade }>30 \\
\mathrm{~km} / \mathrm{h}\end{array}$ \\
\hline & & & & $\begin{array}{c}\text { vias com } \\
\text { calçadas } \\
\text { segregadas } \\
\text { velocidade } \leq 30 \\
\mathrm{~km} / \mathrm{h}\end{array}$ & $\begin{array}{c}\text { vias com calçadas } \\
\text { segregadas } \\
\text { velocidade } \leq 50 \\
\mathrm{~km} / \mathrm{h}\end{array}$ & $\begin{array}{c}\text { vias com calçadas } \\
\text { segregadas } \\
\text { velocidade }>50 \\
\mathrm{~km} / \mathrm{h}\end{array}$ \\
\hline & \multirow{3}{*}{$\begin{array}{l}\text { Segurança } \\
\text { Pública }\end{array}$} & $\begin{array}{l}\text { lluminação } \\
\text { Pública* }\end{array}$ & $\begin{array}{l}\text { resultado da } \\
\text { avaliação = } 100\end{array}$ & $\begin{array}{l}\text { resultado da } \\
\text { avaliação = } 90\end{array}$ & $\begin{array}{l}\text { resultado da } \\
\text { avaliaçāo }=60\end{array}$ & $\begin{array}{c}\text { resultado da } \\
\text { avaliaçāo }=<60\end{array}$ \\
\hline & & $\begin{array}{l}\text { Fluxo de } \\
\text { Pedestres }\end{array}$ & $\begin{array}{l}\text { nos turnos diurno } \\
\text { e noturno em } \\
\text { todos os dias da } \\
\text { semana }\end{array}$ & $\begin{array}{l}\text { em um dos turnos } \\
\text { (diurno ou } \\
\text { noturno) em } \\
\text { todos os dias da } \\
\text { semana } \\
\end{array}$ & $\begin{array}{l}\text { em um dos turnos } \\
\text { (diurno ou noturno) } \\
\text { durantes dias uteis ou } \\
\text { finais de semana e } \\
\text { feriados }\end{array}$ & $\begin{array}{c}\text { ausência de } \\
\text { pedestre em } \\
\text { diferentes turnos e } \\
\text { dias de semana }\end{array}$ \\
\hline & & $\begin{array}{l}\text { Câmeras de } \\
\text { Segurança** }\end{array}$ & presença & & & ausência \\
\hline & \multirow{4}{*}{$\begin{array}{l}\text { Proteçāo } \\
\text { Física }\end{array}$} & $\begin{array}{l}\text { Localização } \\
\text { do espaço } \\
\text { infantil** }\end{array}$ & $\begin{array}{l}\text { central e com } \\
\text { cercamento }\end{array}$ & $\begin{array}{l}\text { central e sem } \\
\text { cercamento }\end{array}$ & $\begin{array}{l}\text { próximo as vias e } \\
\text { com cercamento }\end{array}$ & $\begin{array}{l}\text { próximo as vias e } \\
\text { sem cercamento }\end{array}$ \\
\hline & & $\begin{array}{l}\text { Material do } \\
\text { piso do } \\
\text { espaço } \\
\text { infantil** }\end{array}$ & $\begin{array}{c}\text { piso } \\
\text { emborrachado }\end{array}$ & $\begin{array}{l}\text { grama natural ou } \\
\text { sintética }\end{array}$ & areia & $\begin{array}{l}\text { piso asfáltico ou } \\
\text { intertravado }\end{array}$ \\
\hline & & $\begin{array}{l}\text { Material dos } \\
\text { brinquedos** }\end{array}$ & $\begin{array}{l}\text { principal material } \\
\text { plástico } \\
\text { rotomoldado }\end{array}$ & $\begin{array}{l}\text { principal material } \\
\text { madeira ou } \\
\text { emborrachado }\end{array}$ & $\begin{array}{l}\text { principal material } \\
\text { concreto }\end{array}$ & $\begin{array}{l}\text { principal material } \\
\text { metal }\end{array}$ \\
\hline & & $\begin{array}{l}\text { Estado de } \\
\text { conservação } \\
\text { dos } \\
\text { brinquedos** }\end{array}$ & ótimo & bom & suficiente & insuficiente \\
\hline \multicolumn{7}{|c|}{$\begin{array}{l}\text { * Cálculo foi obtido através da soma das notas +20 quando há pontos de iluminação voltados para a rua +40 quando há pontos } \\
\text { de iluminação dedicados ao pedestre }+40 \text { quando há pontos de iluminação nas travessias ou árvores ou lâmpadas quebradas. } \\
\text { ** Indicadores acrescidos pelo grupo de pesquisa } \\
\text { *** O período de contagem para o fluxo de pessoas foi o de } 15 \text { minutos, entre às } 15 \text { he } 17 \text { h, durante os meses de dezembro } 2018 \\
\text { a março de } 2019\end{array}$} \\
\hline
\end{tabular}


Após a identificação e mapeamento dos espaços para brincar da Regional estudada, cada um dos espaços foram visitados, fotografados, filmados e, por meio da observação, foram coletados os dados necessários para a análise.

\section{ANÁLISE DOS ESPAÇOS PARA BRINCAR}

Conforme ilustrado na Figura 1, a região possui 20 praças, distribuídas em 21 bairros, sendo 01 delas com total ausência de espaços para brincar (playground, quadra ou pista de skate). Dentre as praças que possuem espaços para brincar (evidenciadas em verde na Figura 1), $95 \%$ delas possuem playgrounds (19), $60 \%$ delas possuem quadras (12) e apenas $5 \%$ possuem pista de skate (1).

Figura 1 - Localização da Regional 2 com espaços para brincar

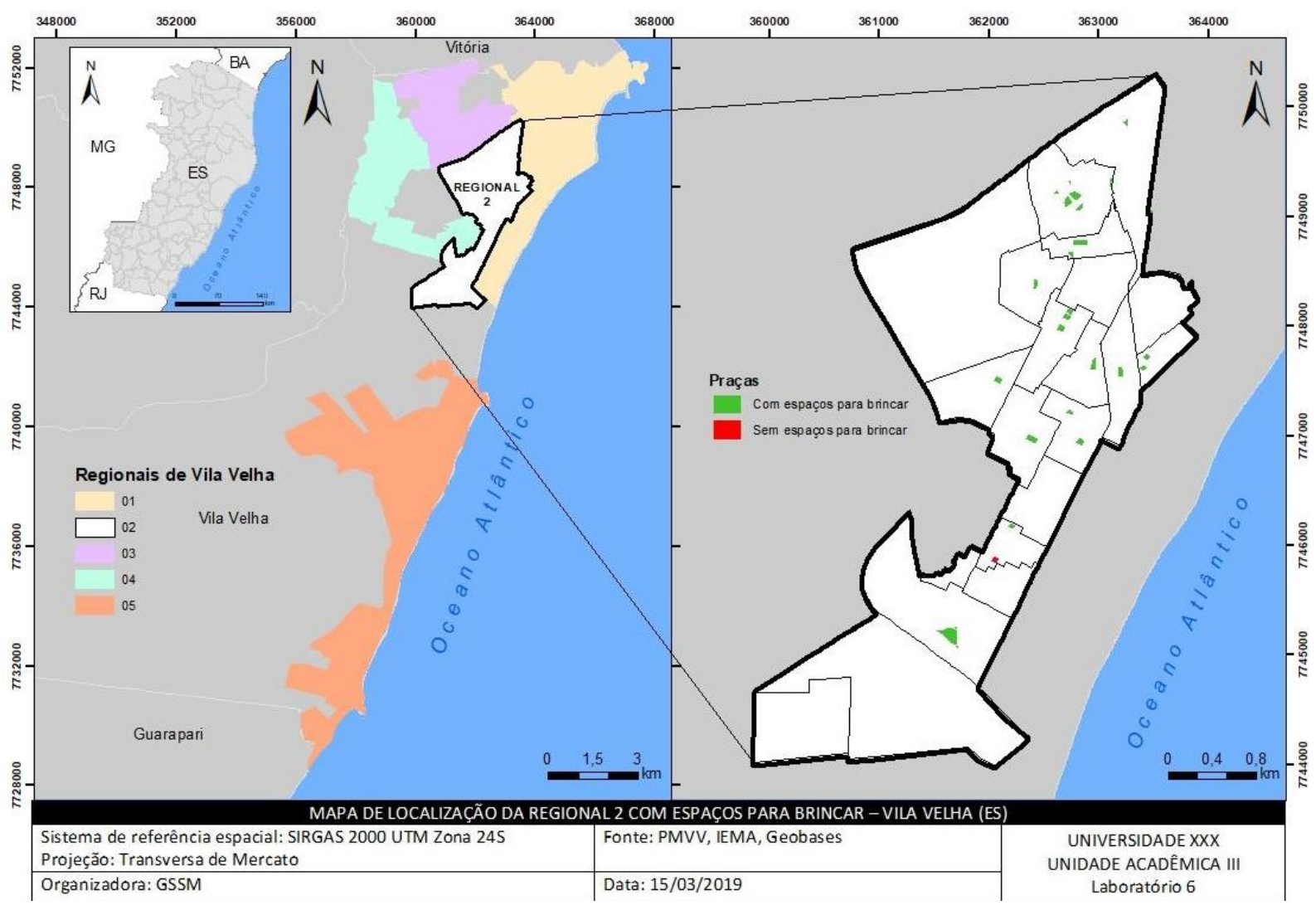

Fonte: Imagem gerada pelo ArcGIS, 2019.

Em relação a categoria "Proteção e Segurança", foi também necessário analisar o entorno das praças visando observar a segurança e as condições de acesso, como iluminação, travessias, fluxo de pedestre, câmeras de vigilância, bem como os aspectos ligados a proteção física: localização do espaço infantil, material do piso do espaço infantil, material e estado de conservação dos brinquedos.

Dos indicadores acrescidos, a presença de câmera é relevante para monitorar a segurança das crianças e demais usuários. Para preservar a segurança física das crianças, os espaços para brincar precisam ser re-cintados e localizados fora do perímetro da praça. O material do piso e dos equipamentos devem ser acessíveis, resistentes e seguros. Além disso, foi necessário observar o estado de conservação dos brinquedos, garantindo brincadeiras seguranças e com ambiência adequada.

A análise resultou que das 20 praças da Regional Grande Ibes, apenas 3 delas (15\%) possuem travessias que cumprem com os requisitos de qualidade (BRASIL, 2018). Em relação ao indicador "tipologia da rua", 60\% das praças obtiveram parâmetros considerados "bom". 
Quanto a "iluminação pública", 14 praças atendem as exigências, ou seja, $70 \%$ delas garantem o uso adequado também no turno noturno. Apenas $30 \%$ das praças alcançaram a melhor nota em relação ao "fluxo de pedestres" e, das 20 praça,s somente 6 (30\%) possuem "câmera de segurança".

No atributo "proteção física", 95\% das praças possuem espaços para brincar localizados próximos às vias e com cercamento, sendo consideradas como "suficiente", já que a situação "ótima" seria espaços situados no interior das praças, garantindo uma melhor proteção. Todas as áreas infantis analisadas possuem piso em areia que - apesar de ser um material que auxilia no impacto e colabora nos estímulos táteis - não é acessível e ainda necessita de maior cuidado em relação a salubridade. No indicador referente ao "material dos brinquedos", $68 \%$ são de madeira e $32 \%$ são de metal, este último considerado como a pior situação. Em relação ao estado de conservação dos brinquedos, $25 \%$ das praças foram consideradas com manutenção precária.

Considerando o sistema de pontuação do próprio iCam (BRASIL, 2018), no qual, a partir dos respectivos parâmetros, adotam-se as notas de 0 (zero) a 3 (três) para os indicadores estudados - conforme o quadro 2 - é possível observar que a nota geral da categoria "Proteção e Segurança" é de 1,4 (considerada suficiente). Percebe-se ainda que a nota de cada indicador em geral é baixa, com exceção da iluminação que obteve nota 2,5 (considerada boa). Os demais indicadores demonstram a necessidade de intervenção nas praças, em especial no que tange a segurança viária para que as mesmas atendam a proteção de segurança.

Quadro 2 - Pontuação por indicador utilizando a classificação ICam.

\begin{tabular}{|c|c|c|c|c|}
\hline Cat. & Atributos & Indicadores & $\begin{array}{l}\text { Pontuação } \\
\text { Média }\end{array}$ & Classificação \\
\hline \multirow{10}{*}{$\begin{array}{l}0 \\
0 \\
\frac{1}{0} \\
0 \\
\frac{0}{5} \\
0 \\
0 \\
0 \\
0 \\
0 \\
0 \\
0 \\
\frac{0}{0} \\
\underline{0}\end{array}$} & \multirow{2}{*}{$\begin{array}{l}\text { Segurança } \\
\text { Viária }\end{array}$} & Travessias & 1,0 & $\begin{array}{l}\text { SUFICIENTE } \\
1 \text { até } 1,9\end{array}$ \\
\hline & & Tipologia de Rua & 1,7 & $\begin{array}{l}\text { SUFICIENTE } \\
1 \text { até 1,9 }\end{array}$ \\
\hline & \multirow{3}{*}{$\begin{array}{l}\text { Segurança } \\
\text { Pública }\end{array}$} & lluminação & 2,5 & $\begin{array}{c}\text { BOM } \\
2 \text { até } 2,9\end{array}$ \\
\hline & & Fluxo de Pedestres & 1,6 & $\begin{array}{c}\text { SUFICIENTE } \\
1 \text { até } 1.9\end{array}$ \\
\hline & & $\begin{array}{l}\text { Câmeras de } \\
\text { Segurança }\end{array}$ & 0,9 & $\begin{array}{l}\text { INSUFICIENTE } \\
0 \text { até } 0,9\end{array}$ \\
\hline & \multirow{4}{*}{$\begin{array}{l}\text { Proteção } \\
\text { Física }\end{array}$} & $\begin{array}{l}\text { Localização do } \\
\text { espaço infantil }\end{array}$ & 1,1 & $\begin{array}{l}\text { SUFICIENTE } \\
1 \text { até } 0,9\end{array}$ \\
\hline & & $\begin{array}{l}\text { Material do piso } \\
\text { do espaço infantil }\end{array}$ & 1,0 & $\begin{array}{c}\text { SUFICIENTE } \\
1 \text { até } 0,9\end{array}$ \\
\hline & & $\begin{array}{c}\text { Material dos } \\
\text { brinquedos }\end{array}$ & 1,4 & $\begin{array}{l}\text { SUFICIENTE } \\
1 \text { até } 0,9\end{array}$ \\
\hline & & $\begin{array}{c}\text { Estado de } \\
\text { conservação dos } \\
\text { brinquedos }\end{array}$ & 1,8 & $\begin{array}{l}\text { SUFICIENTE } \\
1 \text { até } 0,9\end{array}$ \\
\hline & \multicolumn{2}{|c|}{ Nota Geral por Indicador } & 1,4 & $\begin{array}{l}\text { SUFICIENTE } \\
1 \text { até } 0,9\end{array}$ \\
\hline
\end{tabular}

Fonte: Os autores, 2019

Os resultados obtidos através da análise por praças referentes à categoria (conforme a Figura 2) indicam a predominância da pontuação "suficiente", evidenciada em amarelo, sendo que 17 praças alcançaram a nota "suficiente" e 3 receberam a pior pontuação da análise "insuficiente" (zero). De acordo com os indicadores e parâmetros de análise estabelecidos, nenhuma praça foi considerada como "boa" ou "ótima", fato esse que assinala e evidencia a necessidade de investimentos maiores nos aspectos ligados a segurança viária, segurança pública e proteção física desses espaços, principalmente para que os mesmos possam incluir as crianças. 
Figura 2 - Pontuação por praças
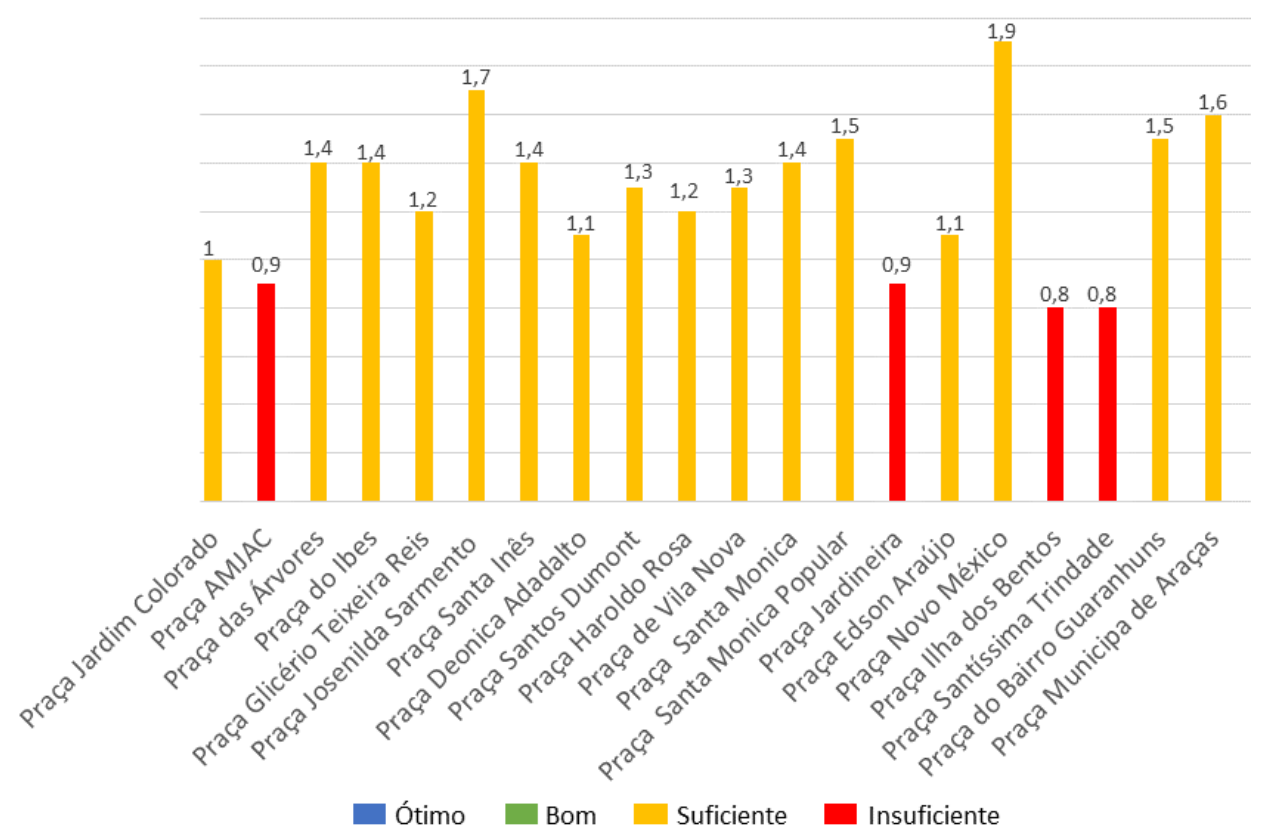

Fonte: Os autores, 2019

As praças que atingiram a pior pontuação da análise foram aquelas que de fato não cumprem os requisitos analisados. A ausência de câmeras de segurança foi o indicador que recebeu a menor pontuação. A praça Novo México foi a melhor qualificada visto que garante a proteção e segurança dos seus usuários mantendo o fluxo ativo, sendo monitorada com câmeras de segurança e travessias que cumprem os requisitos da análise. Possui ainda "boa" iluminação pública, mantendo a conservação dos espaços para brincar, apesar dos indicadores "material do piso infantil" e "localização da área infantil" terem sidos avaliados como "suficiente".

\section{CONSIDERAÇÕES FINAIS}

A cidade deve buscar entender a importância da qualidade dos espaços para brincar e unir aspectos necessários para o reconhecimento das infâncias contemporâneas. Entretanto, conforme constatado, as áreas infantis da regional Grande lbes ainda carecem de planejamento e expansão, com evidência para os aspectos ligados a proteção e segurança.

A análise apresentada fornece ainda aspectos fundamentais para elaboração de diretrizes que possam ser aplicadas nos espaços para brincar, visando também o desenvolvimento de cidades mais inclusivas.

\section{AGRADECIMENTOS}

As autoras agradecem a Universidade Vila Velha-ES (UVV) pelo apoio concedido e a equipe do Grupo de Pesquisa Paisagem Urbana e Inclusão.

\section{REFERÊNCIAS}

BRASIL. Índice de Caminhabilidade Ferramenta - ITDP, Versão 2.0. Rio de Janeiro, 2018.

COTRIM, G. S. \& Bichara, I. D. (2013). O Brincar no Ambiente Urbano: Limites e Possibilidades em Ruas e Parquinhos de uma Metrópole. Psicologia: Reflexão e Crítica, 26(2), 388-395. Universidade Federal da Bahia, Salvador, Brasil. 
DIAS, Marina Simone. Em busca dos espaços públicos de brincar: um estudo das infâncias contemporâneas na cidade de Vitória-ES. Pós, Rev. Programa Pós-Grad. Arquit. Urban. FAUUSP. São Paulo, v. 25, n. 45, p. 102-117, jan-abr 2018.

IBGE - Instituto Brasileiro de Geografia e estatística. Censo Demográfico, 2010. Disponível em: $<$ https://www.ibge.gov.br/cidades-e-estados/es/vila-velha.html? $>$. Acesso em: 10 mar. 2019.

MEDEIROS, Adriana Araujo et Al. Acessibilidade inclusiva no parque infantil arruda câmara, p. 739-750. In: Anais do VI Encontro Nacional de Ergonomia do Ambiente Construído \& VII Seminário Brasileiro de Acessibilidade Integral [=Blucher Design Proceedings, v.2 n.7]. São Paulo: Blucher, 2016.

SARTORI, Gabriela Dias; ALVEZ, Fernando Donizete; SOMMERHALDER, Aline. A cultura lúdica infantil em parques públicos: Qual o espaço e tempo para brincar? Educação Unisinos. 19(3):401-408, setembro/dezembro 2015.

SEMPLA - Secretaria Municipal de Planejamento, Orçamento e Gestão. Perfil Socioeconômico por Bairros, 2013. Disponível em:

<http://www.vilavelha.es.gov.br/midia/paginas/Perfil\%20socio\%20economico\%20R2.pdf> Acesso em: 17 mar. 2019. 